\title{
COVID-19 PANDEMIC: A CHALLENGE TO A CHILD WITH CANCER
}

\author{
R. Nerli ${ }^{1}$, Adarsh Sanikop ${ }^{1}$, Manas Sharma ${ }^{1}$, and Shridhar Ghagane ${ }^{1}$ \\ ${ }^{1}$ KLE Academy of Higher Education and Research
}

May 29, 2020

\section{COVID-19 PANDEMIC: A CHALLENGE TO A CHILD WITH CANCER}

Dear Editor,

People of all ages can be infected by the new coronavirus (2019-nCoV). Older people, and people with pre-existing medical conditions (such as asthma, diabetes, heart disease) are more vulnerable to becoming severely ill with the virus. There is a widespread anxiety among families of children with cancer due to risk of exposure to SARS-CoV-2, either in the hospital or community setting. ${ }^{[1]}$ Recently Ogimi et al ${ }^{[2]}$ reported that infants and younger children (i.e., [?]5 years) are more likely to develop severe clinical manifestations than older children, maybe due to immaturity of the immune system. Sullivan et al ${ }^{[3]}$ reported that the COVID-19 pandemic was one of the most serious global challenge to delivering affordable and equitable treatment to children with cancer. They have provided some practical advice for adapting diagnostic and treatment protocols for children with cancer during the pandemic, the measures to be taken to contain it (e.g. extreme social distancing) and how to prepare for the anticipated recovery period.

The Government and administrative measures such as lockdown has further compounded these challenges. Lack of state transport, closure of district borders, non-availability of medications has put these children at risk of rapid growth of disease, delay in treatment and poor outcome. A four and half year-old child, a known case of synchronous bilateral Wilms tumour, having undergone bilateral nephron sparing surgery was on adjuvant chemotherapy. The COVID-19 pandemic brought about an interruption in his chemotherapy schedule in January 2020. When he presented in early May, he had a small swelling of $1.5 \mathrm{~cm}$ diameter below the left subcostal margin (Figure 1a). Ultra sonography revealed a hypoechoic lesion below the skin measuring $1.5 \mathrm{~cm}$ in diameter (Figure 1b). Fine needle aspiration cytology was done which revealed sheets of cells with high nuclear/cytoplasm ratio (Figure 1c). The features were highly suspicious of a malignant lesion. The lesion was excised and histo-pathological examination revealed a metastasis from WILMS tumour (Figure 1d). The child has been resumed on further chemotherapy.

Most childhood cancers behave aggressively and need immediate treatment, often requiring prolonged periods of intensive multiagent chemotherapy. Postponement of treatment such as surgery, radiation and chemotherapy is not a safe option in children. There is an urgent need amongst health professionals and families for informed guidance on the range of reasonable and safe adaptations to their services and cancer treatment during the pandemic.

Conflict of Interest: None.

Compliance with Ethical Standards.

\section{REFERENCES:}

1. Kotecha RS. Challenges posed by COVID-19 to children with cancer.Lancet Oncology 2020;21 : e235. 
2. Ogimi C, Englund JA, Bradford MC, et al. Characteristics and outcomes of coronavirus infection in children: The role of viral factors and an immunocompromised state. Journal of the Pediatric Infectious Diseases Society 2019;8 (1):21-8.

3. Sullivan M, Bouffet E, Rodriguez-Galindo C, Luna-Fineman S, Khan MS, Kearns P, Hawkins DS, Challinor J, Morrissey L, Fuchs J, Marcus K. The COVID-19 pandemic: A rapid global response for children with cancer from SIOP, COG, SIOP-E, SIOP-PODC, IPSO, PROS, CCI, and St Jude Global. Pediatric Blood \& Cancer. 2020: e28409.
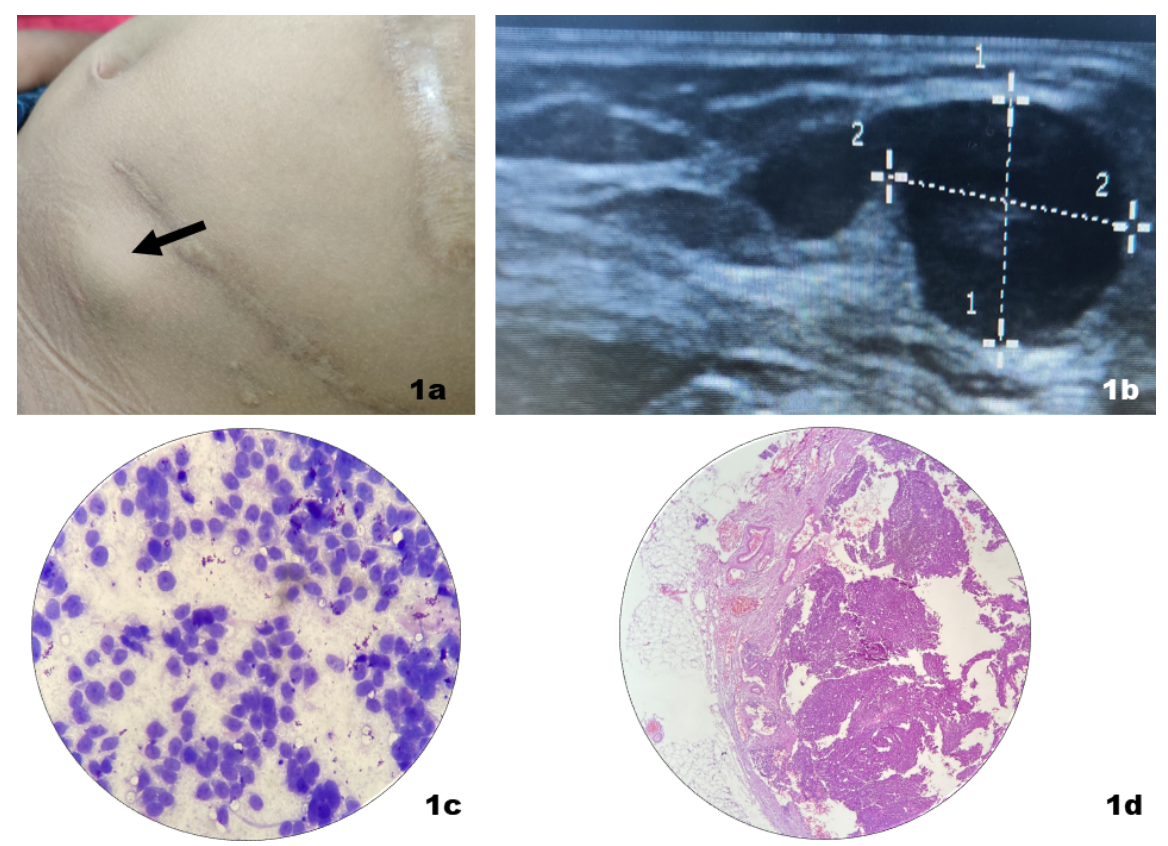

1d 